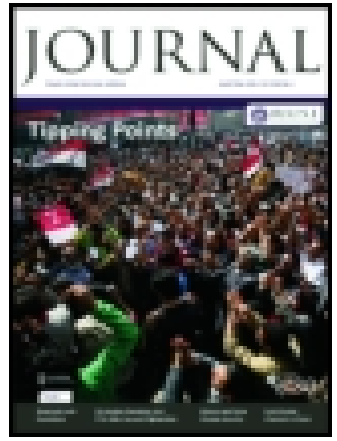

Royal United Services Institution. Journal

\title{
On the Comparative Merits of the Rifled Small Arms of England, France, and the United States; With Remarks on the Various Modes of Grooving Rifle-Barrels
}

\section{J. Boucher Esq.}

To cite this article: J. Boucher Esq. (1858) On the Comparative Merits of the Rifled Small Arms of England, France, and the United States; With Remarks on the Various Modes of Grooving Rifle-Barrels, Royal United Services Institution. Journal, 2:6, 160-177, DOI: 10.1080/03071845809415904

To link to this article: http://dx.doi.org/10.1080/03071845809415904

曲 Published online: 11 Sep 2009.

Submit your article to this journal $₫$

Џll Article views: 4

Q View related articles $\longleftarrow$ 
Friday, April 9th.

Irs Grace the DUKE of NORTIUUMBRLAND, K.G., F.R.S., President, in the Chair.

ON THE CONIPARATIVE MERITS OF THE RIFLED SIIALL ARIIS OF ENGLAND, FRANCE, AND THE UNITED STATES; WITH REMARKS ON THE VARIOUS MODES OF GROOVING RIFLE-BARRELS.

Bx J. Bouchen, Esq.

For many years I have carried on expensive and laborious experiments, and have never asked the British authorities for any assistance whatever. All I asked was that the results of my labour might have a fair test. I had the sanction of the Chief of the War Department for this purpose, and a fair trial was no doubt meant by his lordship; and a fair trial the report must have led him to believe that I liad.

As regards expense, I had represented to the War Department that the cost of the dises would not be above a third of that of either cups or plugs. The Enfield Committee, it will be seen, deny this, for they say that "they do not see that my bullet has any advantages over the Service one, so far as the manufacture is concerned." As one or other of these reports must be wrong, let me beg attention to the following simple facts:-

The number manufactured at present is about a million and a-half weekly, which, at $2 s .6 d$. per thousand, makes $187 l$. 10s. The same number of dises would cost only $37 l .10$ s.; so that $150 l$. per week, or 7,700l. per annum, might even now be sived.

$\Lambda$ bullet may be regarded as a reservoir of force or motion, always ready to return as much as it has received. The quantity of its motion, measured by its velocity and quantity of matter, is also the measure of the degree and direction of the force or fores which produced it, and of the force or momentum which the bullet can exhibit again when opposed or made to act itself as a cause. 'The 
force of a bullet's motion is, therefore, preciscly equiralent to the force expended in producing it. It is as if a transfer of the principle of forec were made from the gunpowder or moving power into the bullet or body moved, as the bullet will be ready to re-produce the whole of the force, and to cause it to opernte on the obstacles which it encounters.

The first obstacle which a leaden bullet has to contend with is the inertia of some of its own parts; then the friction or rubbing of its sides on the sides of the barrel; the condensed air in front of it in the barrel; and then again the resistance and friction of the air and gravity outside the barrel. These obstacles are all more or less increased or diminished by the peculiar shape and length of the bullet; but all being caluses of retardation, they will continually destroy a portion, more or less, of that force of motion in the bullet, which was nevertheless originally precisely equal to the force expended by the powder in putting it in motion.

In any mass of matter, however irregular may be its form, there are at least three lines round which its parts are so arranged, that, if it be made to revolve upon either of them as an axis, the centrifugal forces are so balanced as to exert no strain upon the axis, and consequently to have no tendency to alter its position. These three axes, which are called the principal axes, are at right angles to each other. Their length will be different in almost every instance; and this difference produces an important influence on their respective properties. When they are all of the same length, the body will rotate equally well on either of them. This is the case, for instance, in a globe, the number of whose principal axes has no limit; but in a body like an elongated bullet, whose principal axes are uncqual in length, it will rotate securely on the shortest of these axes only; that is, if whilst rotating upon its longest axis it be slightly thrown out of its position it will have no tendency to recover itself, but will alter its condition altogether, and will revolve around its shortest axis. For the same reason, if whilst rotating around the shortest axis it receive any disturbance, it will not now change to any other axis, but will recover itself, and thus constantly tend to maintain its position round its shortest axis.

This principle may be fumiliarly illustrated by a simple expe- 
riment made upon an ordinary sea-shore pebble. Let us suppose this to be of a regular oval form, having two suifaces somerhat rounded. The three principal axes of such a pebble will be1. The long dinmeter of the oval side, or the line joining its two furthest points: 2. The short diameter of the oval side, or the line joining its two nearest points: 3 . The line joining the centres of the two sides, thus crossing the thickness of the pebble. Now we can spin such a pebble upon one of its ends-that is, around its longr diameter-as an axis; but it will be very unstendy, and that in proportion as the force applied is less, and the slightest variation of its position will orerturn it altogether. The same will occur when it is spun upon the side edge; that is, around its short dianeter; but when it is spun mpon one of its rounded surfaces it has no tendency to fall over, since it is then revolving around its shortest diameter, and, if disturbed, it will return to the same position; hence the axis around which a body of any form is in rotation, will always tend to change into the direction of its shortest principal axis, and will then remain settled.

This experiment may not be resarded as fully illustrating the principle, since, when the axis is supported from below, the tendency of the centre of gravity towards the lowest possible point will naturally cause the body to assume that position. But the same thing happens when the change of the direction of the axis is such as to leave the centre of gravity where it was; and it will even take place when it cannot occur without raising the centre of gravity. Thus, let a body be suspended, hanging by a string, frely from any point which is not the extrenity of its shortest principal axis of rotation. Now, if we make the body rerolve with sufficient rapidity, it will not rotate around the axis in which it was hanging, but about its shortest axis, which is the line that crosses its thickness, through its centre; and it will do this. with so great a force, (if the motion be sufficiently rapid,) as to overcome the weight of the body which tends to keep it in its frrst vertical position, so that it will gradually lift itself up, bringing its rotation continually nenrer to its shortest principal axis; until it will (so far as the eye can perceive) find that axis, and will rotate about it: its centre of gravity thus becoming as high as the point of suspension. 
Fig: 1.

Fig. 2

Fï.3.
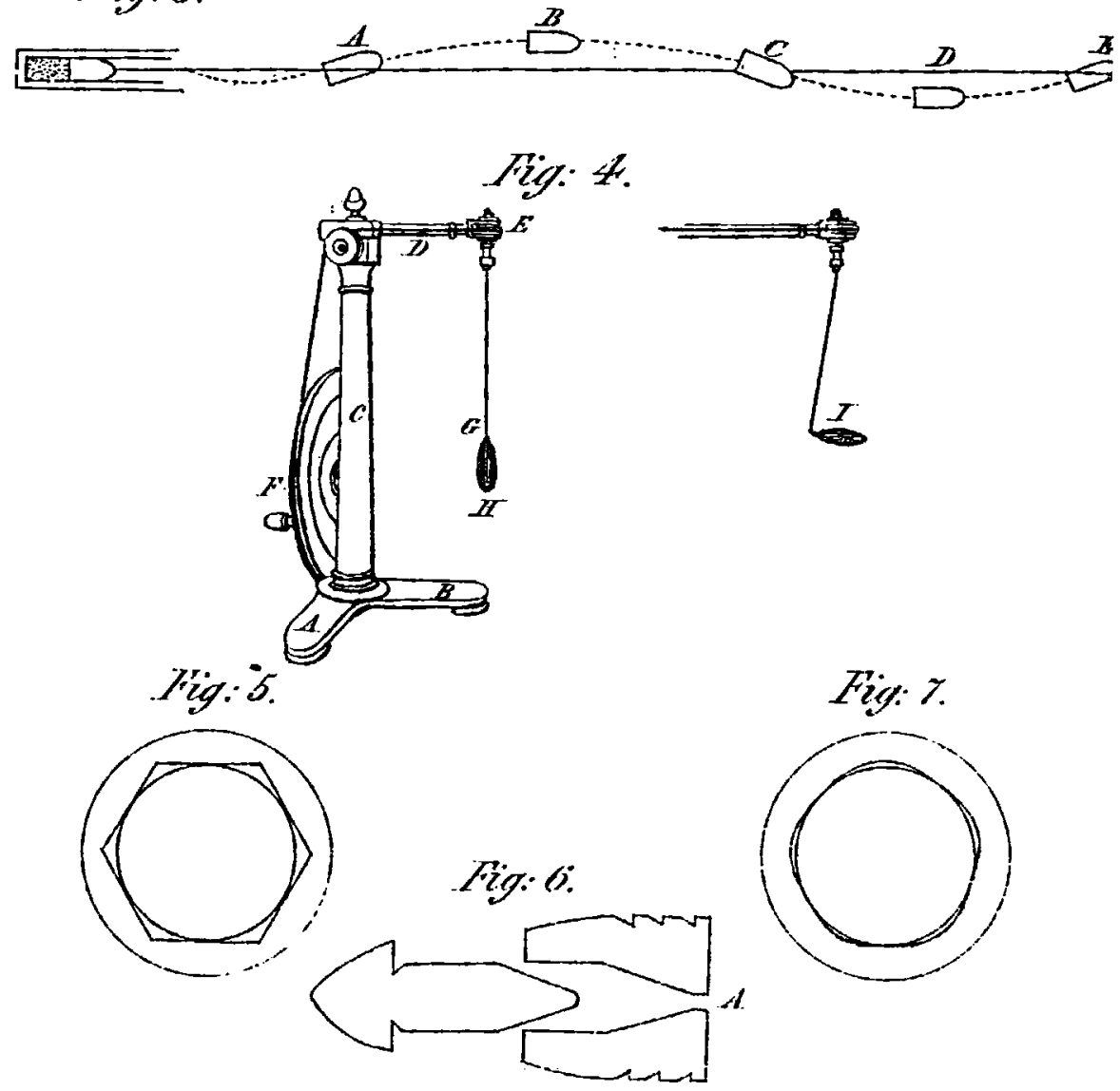
A very simple machine may be constructed $f_{i} \wedge m$ the sketch Fig. 4, which will clearly explain this rotation.

Upon the stand $\Lambda \mathrm{B}$. is fixed the pillar $\mathrm{C}$, carrying an horizontal arm, $\mathrm{D}$; at $\mathrm{E}$ there is a small pulley, turned by the multiplying wheel $\mathrm{F}$, which is moved by the handle, near its circumference. To the pulley $E$ a string is attached, to which bodies of various forms may be suspended, from any other axes than their shortest permanent axes. On turning the whecl, the body will not rotate about the axis G II, but will alter its position, continually approaching to a rotation about its shortest principal axis as represented at I; raising, as 1 have already stated, its centre of gravity as high as the point of suspension.

The reason of this curious property is easily explained when the principles of centrifugal force are understood. When a body is revolving round its longest axis, the parts composing its mass are disposed in such a manner as to be at the least possible distance from the axis. On the other hand, when it is rotating about its shortest diameter, the parts are so arranged as to be at the greatest possible distance from the axis. Now it is a property of centrifugal force that it causes the parts of at revolving body to dispose themselves at the greatest possible distance from the ecntre; and this will be the ense, therefore, when the rotation is round the shortest axis.

These principles being thoroughly understood, there will be no difficulty in applying them practically to the motion of projectiles of any given leugth. Long bullets never range far correctly, unless fired out of barrels having very rapid deep spirals, with a corresponding rapid propelling force, to counteract the greater tendency which such bullets liave to rotate round their shortest axis. This is exemplified in England in MIr. Whitworth's hexagonal rifle. Iis bullets are 3 calibres in length: but the twist of the grooves is rapid in proportion, being 1 turn in 20 inches, and very deep, with heavy charges of powder, considering the calibre of the barrel, which is not half an inch, including even the depth of the grooves; for the hexagonal angles are merely grooves in disguise; and, moreover; very objectionable grooves in shape, as may be seen by referring to Fig. 5, the inner cirele representing the end of a bullet, so as to distinguish the depth and shape of the grooves more clearly. 
Colonel Jacob's bullets were also at one time made very long, with a rapid spiral, decp grooves, and heavy charges; but he has lately made a change, haring found that his former system was radically wrong. His bullets are still, lowever, as long as 21 calibres, with a deep spiral of 1 turn in 3 fect. In France long bullets have also been tried, and found to require a very rapid.spiral. All these bullets may be said to be solid, baving their centres of gravity in the hind part; for Mr. Thitworth's bullet, though it has a slight hollow in its base, would be better to have none, as no cavity of any depth could withstand the shock of the explosion of such charges, resisted as the bullets must be by the enormous friction which a long bullet and deep grooves crente.

It is reported that "Mr. Whitworth discovered in the course of his experiments, that according to the quickness of the turn in the polygon (or grooves) is the length of the projectile that may be fired." In order to tench the principles of elongated projectiles and rifling correctly, Mr. Whitworth should have reserved his observation, by saying that, "the longer the bullet intended to be used, the more rapid the turn or twist of the grooves shov'd be made." Had he been compelled to adopt the same large calibre as the Enfield rifle, his practice Iately compared with that weapon wonld have told a rery different tale.

If a long bullet were fired out of a barrel having a slow spiral, the result would be, that ere it ranged to any considerable distance its rotatory powrers wonld be gone. But why? That point which constitutes the centre of gravity in any bullet is also the centre of inertia, and, although not in every instance, it is in this case also the centre of motion, and is, therefore, the point in any projectile which traces the line called the trajectory. This point then, in flying through the air, instend of rising and falling as represented in the dingrams Nos. 2 and 3, will pass steadily on, describing the trajectory, while both ends of the longest axis of the bullet which passes through this point will trace a spiral circle round the trajectory, if the motion of rotation be comparatively slow; but this circle will be closer to that line as the motion of rotation is made more rapid. If the motion of rotation, howerer, has been made sufficiently rapid, the spinning of the axis will then be motionless, and will form as it were a perfect tangent to the curve. 
A bullet can only be made to adopt this most fivourable position by bringing to its aid a happy combination of cxcellences-such as the most suitable calibre and length of barrel; the number, form, and twist of the grooves; the quality and quantity of the powder; and the shape, length, and fitting of the projectile itself. If these are not in harmony the one with the other, $a$ very high derree of excellence in practice will never be the result.

With a slow spiral the motion of rotation will be rendered still slower, in consequence of the additional friction which a long bullet sustains in passing through the barrel; the ends of the bullet will, therefore, from its great length and tendency to return to its shortest axis, trace a more open circle round the line of the trajectory, offering a great surface to the resistance of the air and the deviating powers to act upon; and these circles, by the continual resistance of the air, will become more and more open-or, in other words, the bullet's original force of rotation round its longest axis will rapidly decrease, and, after adopting a number of spontaneous axes, it will finally settle in the shortest axis which can be obtained, and this is the most unfarourable position for long and accurate ranges.

This sort of motion is very distinctly perceived in the common spinning-top. If of homogeneous material and symmetrical form, it will revolve steadily in the same position until the friction of its point with the surface on which it rests affects its motionless appearance: it will then begin, as it were, to acquire life-opening out its top centre with a circular spiral motion more and more, its point doing the same; then rotating umstendily, until at last it falls on its side, upon which it will continue to rotate until friction and the resistance of the air stop it.

Here, then, we have an explanation of the real motion of an elongated bullet while passing through the air, and why very long bullets require a more than ordinary rapid spiral, and, as a matter of course, a great propelling force to drive them through the barrcl. But no real benefit can accrue from such extreme practices, as the bullets, being heavier, are more expensive; they require more powder to give them the necessary degree of velocity; the recoil, caused by the resistance in passing through the barrel, is augmented, deranging the aim of the marksman; and, further, very

YOL. II. 
long bullets add unnecessarily to the weight which the soldier has to carry.

These remarks apply ouly to very long bullets, compared with those of medium length; as some of the latest French bullets (ns Captain Nesler's, for instance) approach so near to the other extreme that they are really not so much as one calibre in length. In such cases the axis of rotation is not at all liable to be disturbed, as the bullet, being shorter than the calibre of the barrel, will rotate round its shortest axis from the very commencement, and it may therefore be fired with advantage from a barrel having a very slight inclination of spiral, compared with that required for longer bullets; but the rauge will be much less, for this simple reason, that such a bullet ns Captain Nesler's cannot have within itself the same quantity of force or momentum. The bullet that was constructed by the last French Commission is certainly somewhat longer than Captain Nesler's; but in consequence of its laving a large cavity, and a deep gorge round its middle, the weight is not much greater than his, namely, about 500 grains, and this for a seven-tenths ( 700$)$ of an inch calibre.

It is difficult to understand why the French authorities should now countenance such very short bullets, considering the large size of the bore; for during a course of experiments which they carricd on a short time ago:(though certainly with very inefficient weapons for experimental purposes), it was found that bullets upwards of two calibres in length could be fired with great precision. The great weight the soldier would have to carry, I believe, is the only cause for such an unscientific mode of procecding.

The Sardinian authorities have lately announced their intention of giving premiums for " the best musket for infantry and riflemen, and for approved inventions connected therewith."

In determining on the best weapon for the infantry and riflemen of the Sardinian or any other army, I think it is desirable, in the first place, to ascertain what number of rounds of ammunition the soldier should carry, and then to see by what menns that number may be reduced in weight for the comfort of the soldier and the ensy transportation of sufficient supplies, and still be made available, in the highest degree, for the benefit of the service. 
Taking it then for granted that the English authorities had good reasons for fixing on 60 rounds, 530 grains to each bullet, as the proper number and weight for a soldier to carry, was it advisable to malse the calibre of the barrel so large as 577 inch? I venture to think that it was not. Yet it must be admitted that the English Commission made a bold step in the right direction when they reduced the calibre from $\cdot 702$ to .577 inch; more especially when we take into consideration the great opposition the Commission had to contend with in reducing the calibre eren so far. In America, however, they have as certainly taken a step in the wrong direction, by increasing the calibre of their rifle from 540 to $\cdot 580$ inch. In France, where the authorities retain their large calibres, they are unquestionably far behind in the march of improvement, as large calibres are not adapted for propelling elongated bullets, of a moderate weight, combined with the best proportions. It is true that in France there are one or two arms having a very small calibre; but there, again, they jump to the opposite extreme.

In constructing a bullet of good proportions, it should be carefully borne in mind that it is not the size and shape of the projectile before it is placed in the barrel, but what these may be on its leaving the muzzle, which constitutes its effetiveness. The English bullet is .960 inch in length; 568 inch in diameter; windage, for paper, \&c. .009 inch; depth of grooves̀, 014 inch; so that, on leaving the muzzle, it will be expanded to 581 inch in thickness, and shortened to about three-fourths of an inch in length. The American bullet is 1.050 inch in length; .577 inch in diameter; windage (no paper being used), $\cdot 003$ inch; depth of groores at the muzzle, $\cdot 005$ inch; so that it would leave the muzzle expanded to $.585 \mathrm{inch}$, and shortened to about seven-eighths of an inch. The French bullets-for it is impossible to select one as the representative of the whole-will generally leave the muzzle expanded to 705 and $\cdot 720$ inch, including the depth of the grooves; but some of them will not be even so much as that in length! 'The result of all this is, that none of these bullets will leave the muzzle of the rifle possessed of the best proportions for long ranges, considering their weight.

With elongated leaden projectiles there are always certain proportions which will be found to lave tho best results-the calibre 
and grooving of the varrel, and the proper quat tity of powder, being taken into account-and experiments alone can detcrmine what these proportions ought to be. Now, as the avcrage weight of the English, French, and American bullets is about 510 grains, a mucl more effective bullet than any of them-both for range and penetrationmay be consiructed by reducing the calibre of the barrel to exactly lalf an inch ( .500 inch), including the depth of the grooves; the bullet being made, say, 1.100 inch in Iength, so as to leave the muzzle about two calibres in length, and not weigh more than from 500 to 520 grains. By increasing the length of the bullet beyoud this point, the initial velocity which is obtained, in consequence of the friction, is insufficient for it to acquire momentum and rotatory motion enough for very long ranges, without resorting to extreme spirals and heavy charges; and these would only destroy the proper shape of the bullet. On the other hand, by reducing the length within this point, the effect would be equally bad, as the momentum would not be sufficient, owing to the lightness of the bullet. So that, by increasing or diminishing the length, no real advantage is gained, but the contrary.

liffles with a half-inch calibre offer very notable advantages, at they can have a greater degree of thickness of barrel without increasing the reight. The charge of porrder can also be reduced without reducing its efficiency, if the spiral is not made too rapid. This naturally leads us to the consideration of that all-important subject, namely, the best mode of Grooving tne BanneL.

It is assumed by some that a very high rotatory velocity should be given to the bullet, in the first instance, in order to ensure a continuance of the rotation to the end of a long range. There is, however, little foundation for such an assumption, unless the bullet be very faulty in form. Indeed, the velocity of the onward movement decrenses much more rapidly than the rotatory motion, as the former creates great resistance, while the latter has only the simple friction of the air to contend with.

A great twist in the grooves of the barrel, to give a long bullet the high rotatory motion. which it requires, is an evil of a most decided character; as the friction, and consequently the opposition to its passage out of the barrel, are very greatly increased, and the 
original shape of the bullet is, in nany instances, iearly destroyed. With bullets formed like Colonel Jacob's and Mr. Whitworth'swith so much twist in the rifle as the former had at one time, and the latter has now-the friction must be enormous; for, even if made of hardened lead to resist the shock, the hinder end will be clriven up on the fore part, to a certain extent, by the force of the gases, before the inertia of the fore part is completely overcome, and, consequently, the bullet will be wedged, as it were, by the pressure behind more firmly into the grooves.

Colonel Jacob says that " his bullet, having its centre of gravity in the hind part, is unsteady, and has a great tendency to fly with the wrong end first; and that, to counteract this perversity, a great twist in the grooves, giving a rapid spiral motion to the bullet in its flight, is absolutely necessary." This is very true; but why not improve the shape of the bullet, and reduce the twist of the grooves? $A$ bullet having its centre of gravity in the hind part requires a greater relocity of rotation to be given to it, in order to overcome its inclination to rotate round its shortest axis, as its want of stability, arising from the resistance of the air in front, will be in proportion to the distance that its centre of gravity is behind the centre of its figure. In like manner, a bullet having its centre of gravity in the fore part will require less turn to keep it true, as its natural stability will be greater. A high rotatory velocity, as I have already said, is absolutely necessary to counteract the tendency which a long bullet has to change its motion of rotation to its shortest axis; but it is absurd to say that a ligh velocity of rotation adds to its porrer.

That the motion of a body, when not retarded by the air or any other opposing causes, will continue for an indefinite period there is the most satisfactory evidence, derived from those cases in which they are reduced to their smallest possible amount. Every reduction, then, in the amount of friction and of the air's resistance is attended with a proportional increase in the continuance of the motion. We look at, and criticise, the form and construction of a bullet before it is placed in the barrel; but it is evident, from the manner in which some barrels are grooved, that those who use them seldom think, when loading, that they are placing the bullet 
in a second mould, where it will get rex soulded before it again leaves the barrel. Let the barrel then be grooved in such a manner as will preserve the cylindrical part of the bullet as smooth as possible, and its motion, both progressive and rotatory, will be considerably prolonged.

It is much to be regretted that under the head of "Grooves" the American Report is so indefinite, and the deductions which have been drawn by them are so inconsistent generally with the result of their experiments. "Of the twenty-three varieties of groores tried in all," says the.Report, "that of gun No. 16 was found to give uniformly the best results with the altered muskets, while it was found to be fully equal to any for the new trial arms with smaller calibres. These grooves were the broadest and shallowest of any submitted to experiment. The general tendency of the results secms to confirm this conclusion, as it was found, in almost cvery instance, that the bronder and shallower grooves gave the better practice, other things being cqual." The Americans adopt a method commeneing at the breech with a depth of $\cdot 015$ inch, and ending at the muzzle with 005 inch; because they say that "it gave less deviation and less 'drop' of the ball than a slope commencing at the breech with 020 inch, and ending at the muzzle with $\cdot 005$ inch."

The French grooves were at that time 020 inch deep at the breech; but that was no argument in favour of a bad system. The English grooves at the present time are 014 inch deep all through; but even that is too deep for any beneficial purpose.

It is admitted by the Americans, that the grooves of $\cdot 015 \mathrm{inch}$ at the breech, decreasing gradually to 005 at the muzzle, made the best shooting. The only uniform deptlss they tried were in other things not equal, the lands boing in every case broader than the grooves-one of the greatest faults which a rifle-barrel can have; and, moreover, a fault which is borne out and proved by the Americans themselves.

"The effect of depth," says the Report, " is best shown by comparing the results obtained with guns Nos. 7 and 12, the former having grooves about $\cdot 007$ inch in depth, and the latter 015 inch; in all other respects these grooves were alike." The grooves of 
both were uniform from breecls to muzzle, and the lands were somewhat wider than the grooves, but the practice certainly told in favour of the shallow grooves.

"The effect of breadth on grooves," the Report further says, "may be seen by comparing the practice made with guns Nos. 15 and 16. The grooves of these guns were alike in every particular except in width-those of No. 15 being narrower than No. 16." The practice here, again, wis decidedly in favour of the broad grooves. Yet, with such results before them, the Americans seem to have had no idea of increasing the number of the grooves, by reducing the space taken up by unnecessarily hroad lands.

$\Lambda$ barrel rifled with a decreasing depth of groove from $\cdot 015$ to $\cdot 005$ would have its upper half at a depth from $\cdot 010$ to $\cdot 005$, just at the place where the full force of the powder and the greatest expansion of the bullet come into operation. This being the case, it is evident from these experiments that the improved shooting is entirely owing to the shallowness of the grooves from the middle of the barrel upwards, and not to the greater depth near the breech. But let us see if this can be proved beyond a doubt by any collateral evidence.

Now experiments prove that the. bullet is not fully expanded at the instant it is removed from its state of rest; nor is the expansion complete until it has travelled up some portion of the barrel. Taking this fact, then, for granted, the first portions of the powder which are ignited will evolve a large volume of gas, which, from its tremendously elastic force, will increase the space. it occupies by pushing forward the unburnt parts of the charge, and also the bullet, to some distance, before that portion of the powder which lies next to the buliet is actually ignited. In doing this the gas will be resisted to a certain extent by the weight and friction of the bullet; and therefore, from its great expansive force and subtle qualities, it will rush, in part, through the grooves, if deep, until the bullet has become so thoroughly expanded by the force of the rest of the charge pressing behind, as to fill the grooves up completely, and so prevent any further escape in that direction. Thus we see that deep grooves at the breech are very great evils; for they nos only reduce the beneficial effects of the charge behind the bullet, by allowing a portion of the gas to escrape, but they add to the resist- 
ance in front of it, by allowing that portion of the gas which does escape to mix with the already condensed air in the barrel, adding to its already great resisting force.

It appears then clear that the American ball practice was not improved in consequence of the groores being designedly made shallow at the muzzle and deep at the breech; but simply because the grooves were less in depth than those in their older arms, they being 20 inch at the breech, and about 012 at the muzzle; and, moreover, that a great portion of each new barrel was made shallower than even their old arms were at the muzzle itself. In fact there appears nothing whatever in the American practice to warrant the conclusions which they came to, when they reported that "the superiority of the decreasing over the uniform depth for grooves is confirmed."

The idea of making the grooves shallower at the muzzle than at the breech is due to Capt. Tamisier, of the French Artillery; but it was merely a work of expediency, to enable the French authorities to convert the muskets of 1842 into rifles. The grooves were made 020 inch deep at the breech, but were graduallydecreased towards the muzzle, where, in consequence of the thinness of the metal, they were made only 004 inch deep.

The French and Americans recommend that "there should be an odd number of grooves, in which case," as they say, " a groove will be opposite to a land; for, when the ball is expanded, cach land," as they tell us, "tends to push the opposite part of the ball into a groove; consequently the ball is less deformed than when the number of grooves is even, when a land would be opposite a Jand, and a groove opposite a groove" This iden originated with the solid à tige bullet of the French; but, as it refers to a soft picce of metal, the argument has no foundation whatever to rest upon. It is therefore a matter of no moment whether the grooves be odd or cven, for that in a great mensure must depend ou the calibre of the barrel, as, the depth being first determined, the grooves should be made broad enough to merge up to very narrow lands, without lenving any sharp edges.

The Americans have adopted "three grooves equal in width to the lands, and rounded in shape" (or rather rectangular, as they 
have square edges), "vihich," the-Report stys, " take a firmer hold on the bullet, with the same depth of cut, than the circular ones;" the circular ones being, of course, as decp only in the centre of the groove as they incline up.gradually to the edges of the lands. Notrithstanding the opinion, however, which the Americans have formed on this important subject, I feel that I have good grounds for dissenting entirely from their conclusions.

By making the groores circulur, and increasing their number, the depth may be reduced by nearly one-half-a very great desideratum -and still have a better and more equal hold on the bullet: the grasp of the spirals, or grooved parts, being nearly doubled. The French have, in the aggregate, more than one inch of the circumference of the bore taken up by the lands alone, the Americans have - 840 inch, and the English hatre $\cdot 945$ inch, which is the cause of a great and unnecessary amount of friction, and consequent retardation in the velocity of the bullet; for be it remembered, that, in the act of expanding, the bullet is also in the act of moving forward; and, until it is fully expanded into the grooves, the pressure and retarding.friction are caused by the lands alone, which, being so brond, must also retard the quick expansion of the lead into the grooves, permitting a greater portion of the gases to escape.

By making the grooves shallow and more numerous, and, consequently, the lands very narrow, we economise the powder (a point of no small importance); as two drachms can then be made as effective as two drachms and a laalf when a portion of the gases is not only permitted to escape, but to create an extra resistance in front of the bullet, instead of being restricted to a pressure behind. As narrow lands offer less resistance to the expansion of the lead-the atoms or particles of lead separating more quickly to one side and the otheranother most important advantage is gained by their adoption; for, as shallow grooves are sooner filled up, the lead of the bullet will be in contact with the bottom of the grooves during nearly the whole period of its motion in the barrel, and its original shape will thus be less liable to be altered or destroyed. Indeed, to this very fact more than ordinary precision is always due.

$\Lambda$ s regards the best degree of spiral, the Americans think that " a grenter twist than one turn in six feet increases the lateral deviation 
of the bullet;" and that "this deviation is variable, increasing in a greater ratio than the distance fired; and that it is greater, as the rotatory motion of the bullet is made more rapid." "In the guns giving a twist of one turn in four and fire feet, it was found necessary to readjust the sights for long distances; therefore, a greater twist than one turn in six feet," they say, "is not necessary nor advantageous." 'This opinion rests, however, upon no true foundation. It is nerely an idea burrowed from the French, along with the rifle $a$ tige and bullet, which the Americans used in making their experiments. In fact, there is nothing in their experiments to warrant such an opinion-especially when we learn that they were carried on not only with the rifle $i$ tige and bullet, but also with a rifle of their old musket calibre, and some bullets of the most unscientific construction imaginable. Fig. 6 represents one of these bullets $-\Lambda$, being a section; $B$, the bullet, with the plug partly inserted, ready for londing.

The French entertain peculinr ideas with respect to the different degrees of twist in the barrel. In trying experiments with long bullets, they report that "in proportion as the ball increases in length, and consequently in weight, grooves with greater inclinations, but smaller charges, should be used." "With weak charges of powder, the twist of the grooves," they say, "may be very great; with powerful charges, the inclination should be very slight." This is certainly very erroneous doctrine; for experience tells us that, in proportion as the bullet is made longer, it is not only indispensable that a more rapid rotatory motion should be given to it, but that the effects of the greater inclination in the spiral will be lost if the propelling force is not also increased. The bullet should, therefore, be driven rapidly through the barrel, or a greater twist in the spiral will be of no avail.

Last year the French Minister of War issued a programme, in which it was announced-1st. That all the infantry musket-barrels were to be cut down to 40 inches, leaving them still one inch longer than the Enfield rifle barrel. 2nd. That they shonld receive four grooves of $\cdot 028$ inch in breadth, $\cdot 008$ inch in depth, and of the same degree of spiral as those already in use-they being a little less than one turn in 6 feet 6 inches. 3rd. That they should have but 
one sight fixed, which was to be fixed on so as to give a convenient point-blank range. 4th. That, as it was not necessary that the fire of infantry soldiers should exceed 600 metres (or 656 yards), it would suffice if the projectile which was destined for them had an accuracy, and a range, appropriate for that distance. 5th. That the special conditions of the projectile should be-not to require the iron cup; to weigh at most 500 grains; and, particularly, to have the lowest possible trajectory.

It would be unfair to criticise this programme too closely, bat still the programme might have been drawn up so as to have cuabled the Commission to carry it out with better results. The turn of the spiral ( 1 in 6 feet 6 in.) is certainly quite enough for so short a range as 650 yards; but the lands are by far too broad, and the bullet too light, for the calibre of the barrel, (it being as much as seven-tenths of an inch in diameter,) to permit of the lowest possible trajectory being obtained. In fact, the trajectory in such a case must be a very high one; much higher, indecd-and their experiments show it-than either the English or the American. It is no wonder, then, that the Commission found it impossible, as they remarked, to satisfy all the conditions which were imposed upon them by the Minister of War.

If friction, and every other kind of resistance, be diminished to the utmost possible limit, so that the bullet may receive the full effects of the charge, and be driven rapidly through the barrel, a comparatively slow spiral may be made the means of giving a rapid rotatory motion to the bullet; for, in such a case, the higher the initial velocity, the greater will the rotatory motion be, as the bullet must pass through the barrel quicker, and therefore take the amount of turn quicker, and, as a matter of course, it will make a greater number of revolutions in a certain portion of time.

There are other and more beneficial modes of obtaining a high velocity of rotation than by rapid twists in the spiral, which of course require deep grooves to prevent the bullet from stripping. Take a three-groved rifle for instance, having the lauds as broad as the grooves, and run a shallow groove up on ench land. The result will be that the bullet will pass out with greater velocity, in consequence of there being less friction; and it will rotate as many 
times in a second as it would have done had it been projected from a barrel with one turn in 5 feet instead of one turn in 6 fcet; and, what is of very great importance, the original shape of the bullet will be less linble to be destroyed.

Taking into consideration then all the experiments which I have made myself, all I have witnessed elsewhere, and all the experimental reports I have read on the subject, I still adhere to the mode of grooving which $I$ adopted and recommended in the autumn of 1853, and which I again bronght before the Enfield authorities in 1855; for as sure as large calibres are giving way to smaller calibres, so sure also will broad lands give way to narrow ones.

The mode of grooving which $I$ then recommended, and still adhere to, is represented by Fig. 7; drawn on a larger scale for the sake of distinctness.

As regards the proper degree of twist, I have found that one turn in 5 feet is ample, but not too much, for a range of one mile, and that a barrel 2 feet 6 inches is length enough for any rifle.

With reference to deer-stalking, I may here observe, that, as the range for that sport is generally limited to a much shorter distance than military rifle firing, a twist in the spiral of one turn in 7 or 8 fect will be quite sufficient to keep the bullet spinning rapidly as long as it will be required; so that, by reducing the degree of twist as much as the circumstances of the case will admit, the velocity is made greater, and the trajectory proportionately lower; this being of as much importance to the deer-stalker as a low trajectory is to the military rifleman.

This mode of grooving a barrcl leaves no sharp edges on the bullet to be affected by the air in its passage to the object aimed at. The barrel is in consequence less subject to fouling. Moreover, the friction in such a barrel is so little, that a properly fitting bullet may be withdrawn with one hand, which, in the three-grooved rifle with broad lands, would require, as we have often seen, two men-one holding the rifle, and the other with both hands at the rod drawing the bullet out.

The Americans some time ago tried a mode of grooving somewhat similar to this; but, though they admit that the shooting was cxcellent, they report that " $\mathrm{it}$ is thought that the lands are too 
narrow and delicate for a service weapon." Any man, however, on looking at the diagram, will see that the groores join the lands so imperceptibly, and are so shallow (being only $\cdot 008$ or $\cdot 010$ inch, according to the size of the bore), that such a weapon might indeed be called a smooth-bore rifle. But, if the Americans still persist in making their grooves so deep as $\cdot 015$ inch in the breech, they would certainly not adopt very narrow lands, as it is impossible to make deep grooves without making the elges sharp; consequently, in such a case, the lands rould be made delicate as well as narrow.

I have had some difficulty in condensing these remarks. I trust, therefore, that every allowance will be made for disjointed parts and abridged explanations. $A$ free and open discussion, however, on so important a subject, supported as it ought to be as far as possible by experiment, is the only plan, I believe, that will keep the British people, as a military power, in the van of all improvement.

Wednesday, April 14th, 1858.

ColoNel YORKE, F.R.S. in the Chair.

\section{INDIA, AS CONNECTED WITH A NATIVE ARNY.}

Br J. Craufurd, Esq. F.R.G.S.

\section{(Abstract.)}

TuE native inhabitants of India consist of two classes-the inlabitants of the plains, who have possessed a large measure of civilisation for certainly not less than 3,000 years; and those of the mountain regions, who are still savages, with few arts and no letters. The more cultivated consist of not fewer than ten nations, speaking as many distinct languages. Of these the most considerable are the IIndi, the Bengali, the Orissan or Cuttack, the Telugu, the Tamul, the Cauarese, the Mahratta, and the Concanee. The wild tribes are still more numerous, and have also their distinct languages.

Of the civilised nations, by far the most numerous and important 